\title{
High Expression of AHSP, EPB42, GYPC and HEMGN Predicts Favorable Prognosis in FLT3-ITD-Negative Acute Myeloid Leukemia
}

\author{
Gang-Zhi Zhua,b Yong-Long Yang ${ }^{\mathrm{b}}$ Yan-Jiao Zhang ${ }^{a}$ Wei Liu ${ }^{c}$ Mu-Peng Lia \\ Wen-Jing Zeng ${ }^{\text {a }}$ Xie-Lan Zhao ${ }^{c}$ Xiao-Ping Chen ${ }^{a}$ \\ aDepartment of Clinical Pharmacology, Xiangya Hospital, Central South University, Changsha, bHaikou \\ People's Hospital and Affiliated Haikou Hospital of Xiangya Medical School, Central South University, \\ Haikou, 'Department of Hematology, Xiangya Hospital, Central South University, Changsha, China
}

\author{
Key Words \\ AHSP • EPB42 • GYPC • HEMGN • FLT3-ITD • Acute myeloid leukemia
}

\begin{abstract}
Background/Aims: Acute myeloid leukemia (AML) is a heterogeneous clonal disease and patients with AML who harbor an FMS-like tyrosine kinase 3 (FLT3) mutation present several dilemmas for the clinician. This study aims to identify novel targets for explaining the dilemmas. Methods: We analyzed four microarray gene expression profiles to investigate changes in whole genome expression associated with FLT3-ITD mutation. Results: We identified 22 differentially expressed genes which are commonly expressed among all four profiles. Kaplan-Meier analysis of the dataset GSE12417 revealed that low expression of AHSP, EPB42, GYPC and HEMGN predicted poor prognosis (AHSP: $\mathrm{P}=0.0317, \mathrm{HR}=1.894$; $E P B 42: \mathrm{P}=0.0382$, $\mathrm{HR}=1.859 ;$ GYPC: $\mathrm{P}=0.0015, \mathrm{HR}=2.051 ; \mathrm{HEMGN}: \mathrm{P}=0.0418, \mathrm{HR}=1.838$ in $\mathrm{GSE} 12417$ test cohort; AHSP: $\mathrm{P}=0.0279, \mathrm{HR}=1.548 ; E P B 42: \mathrm{P}=0.0398, \mathrm{HR}=1.505 ; \mathrm{GYPC}: \mathrm{P}=0.0408, \mathrm{HR}=1.501 ; H E M G N$ : $\mathrm{P}=0.0143, \mathrm{HR}=1.630$ in GSE12417 validation cohort). When patients were FLT3-ITD positive, the expression of FLT3 was significantly increased (all $\mathrm{P}<0.05$ in four profiles), and correleation analysis of four profiles revealed that the expression of the four candidate genes negatively correlated with FLT3 expression. Conclusions: Our findings suggest that AHSP, EPB42, GYPC and HEMGN may be suitable biomarkers for diagnostic or therapeutic strategies for FLT3-ITDpositive AML patients.

(C) 2017 The Author(s)

Published by S. Karger AG, Basel
\end{abstract}

\section{Introduction}

Acute myeloid leukemia (AML) is a most common form of hematological malignancy characterized by uncontrolled proliferation of abnormal blast cells or hematopoietic myeloid progenitor cells $[1,2]$. Cytarabine (also named as cytosine arabinoside, Ara-C) combined 


\section{Cellular Physiology Cell Physiol Biochem 2017;42:1973-1984 \begin{tabular}{ll|l} 
DOI: 10.1159/000479837 & and Biochemistry \\
Published online: August 07, 2017 & $\begin{array}{l}\text { O 2017 The Author(s). Published by S. Karger AG, Basel } \\
\text { www.karger.com/cpb }\end{array}$
\end{tabular} \\ Zhu et al.: Favorable Prognosis Markers in FLT3-ITD-Negative AML}

with antracyclines are the most common chemotherapies in the treatment of AML for more than 40 years. Complete remission (CR) rate is about $70 \%$, of which about $60 \%$ of patients relapse and die of their disease. There are many factors that contribute to the difference in chemotherapy efficacy and prognosis among patients with AML, among which genetic factors [3] and chemotherapy resistance $[4,5]$ are the most important factors.

As with other tumors, molecular and cytogenetic profiles are used to guide the clinical treatment of AML [6]. Presently, analysis of molecular abnormalities provides one of the most crucial prognostic information at diagnosis for AML patients [7, 8]. Numerous somatic mutations have been discerned in AML. Somatic mutations in gene encoding nucleophosmin (NPM1), CCAAT/enhancer binding protein alpha (CEBPA) and fms-related tyrosine kinase 3 (FLT3), DNA (cytosine-5-)-methyltransferase 3 alpha (DNMT3A) [9], tet methylcytosine dioxygenase 2 (TET2) [10], isocitrate dehydrogenase 1/2 (IDH1/2) [11,12], additional sex combs like 1 (ASXL1) [13] and PHD finger protein 6 (PHF6) $[14,15]$ have been implicated as well-established genetic marker in AML $[16,17]$.

FLT3 gene, which plays a key role in normal hematopoiesis, is mutated in a third of AML cases [18]. There are two major mutations categories, in-frame duplications within the juxtamembrane region (FLT3-ITD) and point mutation in the tyrosine kinase domain (FLT3-TKD). Approximately 30\% of AML patients harbor some form of FLT3 mutation, 25\% of AML patients carry FLT3-ITD mutation and 7\% of AML patients carry FLT3-TKD mutation. These mutations lead to constitutive activation of the receptor, and then lead to distinctive prognostic effects. A mass of studies have confirmed that FLT3-ITD was an independent predictor of higher relapse rate and poorer overall survival (OS) [18]. However, the mechanism by which this mutation affects prognosis is still vague, suggesting that additional correlation factors reflecting differences in the spectra of associated cooperating mutations as well as differences in signaling pathways downstream of FLT3 impacting disease biology need to be recognized.

In the present research, we analyzed four microarray gene expression profiles to investigate changes in gene expression associated with FLT3-ITD mutation and identify novel target for AML diagnosis and treatment. We identified 22 differentially expressed genes in AML that are commonly expressed among all four profiles. Kaplan-Meier analysis of GSE12417 dataset revealed that gene expression of AHSP, EPB42, GYPC and HEMGN were correlated with disease prognosis, which was coincident with the results in clinically applicable analysis. Correlation analysis of four profiles revealed that all four candidate genes expression negatively correlated with FLT3 expression, suggesting that AHSP, EPB42, GYPC and HEMGN may be suitable biomarkers for diagnostic or therapeutic strategies for FLT3-ITD- positive AML patients.

\section{Materials and Methods}

\section{Affymetrix Microarray Data}

Four microarray datasets were included and three of them are available in the ArrayExpress database (http://www.ebi.ac.uk/arrayexpress) [19] under accession number E-TABM-1029, which included 38 FLT3ITD-positive normal karyotype (NK) AML samples and 79 FLT3-ITD-negative NK-AML samples, and in the Gene Expression Omnibus (GEO) database (https://www.ncbi.nlm.nih.gov/geo/) [20] under accession number GSE15434, including 90 FLT3-ITD-positive NK-AML samples and 161 FLT3-ITD-negative NK-AML samples, and GSE61804, which included 50 FLT3-ITD-positive AML samples and 236 FLT3-ITD-negative AML samples. Moreover, we also used public The Cancer Genome Atlas (TCGA, http://cancergenome.nih. gov/) data repositories as our source of samples [21], including 48 FLT3-ITD-positive AML samples and 122 FLT3-ITD-negative AML samples. A total of 831 AML samples were included in the study. The platform of four datasets is Affymetrix Human Genome U133 Plus 2.0 Array(HG-U133_Plus_2, GPL570). The original CEL files as well as the probe annotation were downloaded from the platform. For prognosis analysis, 242 NK-AML samples having prognosis information were included in survival analysis in GSE12417 dataset. There were two sample sets in GSE12417, which included test and training dataset. In test dataset, 


\section{Cellular Physiology Cell Physiol Biochem 2017;42:1973-1984 \\ \begin{tabular}{ll|l} 
DOI: 10.1159/000479837 & $\begin{array}{l}\text { O 2017 The Author(s). Published by S. Karger AG, Basel } \\
\text { www.karger.com/cpb }\end{array}$ \\
and Biochemistry Published online: August 07, 2017
\end{tabular}}

Zhu et al.: Favorable Prognosis Markers in FLT3-ITD-Negative AML

analysis of 79 samples of bone marrow (BM) or peripheral blood mononuclear cells (PBMCs) from adult patients with untreated AML using GPL570 platforms. In training dataset, 163 samples of BM or PBMCs from adult patients with untreated AML were analyzed with two different platforms: Affymetrix Human Genome U133A Array (HG-U133A, GPL96) and Affymetrix Human Genome U133B Array (HG-U133B, GPL97). Detailed information used for these datasets were described in Table 1.

\section{Analysis of Differently Expressed} Probes (DEPS)

The probe-level data in CEL files were converted into expression profiles in $\mathrm{R}$ software (https://www.r-project. org/) and the robust multiarray average (RMA) algorithm with affy package was used to correct and normalize expression profiles data. Due to one gene has one or more corresponding probe sets, which have a plurality of expression values, the gene expression values reflect the averaged values of those probe sets [22]. All patients were classified into FLT3ITD positive and negative groups. When meeting the criterion of |fold change $\mid \geq 2.0$ and $P$ value $<0.05$, genes were considered differentially expressed. Thenceforth, DEPs among 4 datasets were merged and 28 overlap DEPs or 22 corresponding

Table 1. Characteristics of all datasets

\begin{tabular}{cccccc}
\hline Data sets & Platform & $\mathrm{n}$ & $\begin{array}{c}\text { FLT3-ITD } \\
\text { positive }\end{array}$ & FLT3-ITD negative & Sample \\
\hline GSE15434 & GPL570 & 251 & 90 & 161 & NK-AML \\
GSE61804 & GPL570 & 286 & 50 & 236 & AML \\
E-TABM-1029 & GPL570 & 117 & 38 & 79 & NK-AML \\
TCGA & GPL570 & 170 & 48 & 122 & AML \\
& GPL570 & 79 & - & - & NK-AML \\
GSE12417 & GPL96 & 163 & - & - & NK-AML \\
& GPL97 & 163 & - & - & NK-AML \\
\hline
\end{tabular}

Fig. 1. Flow chart of the procedure for the literature search. DEPs: differentially expressed probes; PPI: protein-protein interaction.

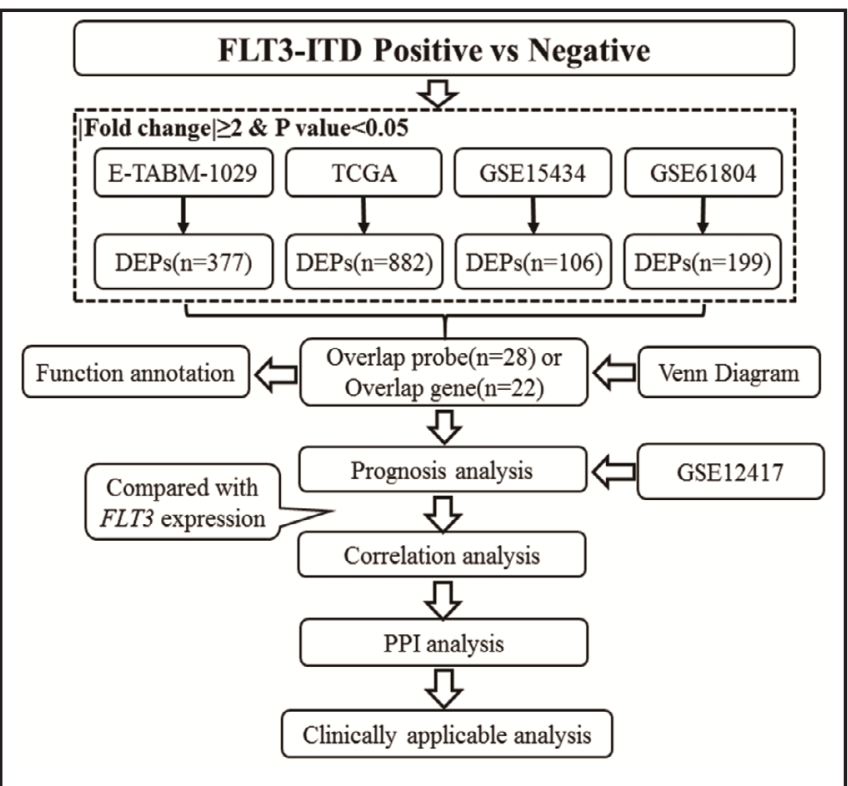
differentially expressed genes (DEGs) were taken out. Further validation of the association between these probes and prognosis was utilized in GSE12417 dataset. Finally, for the purpose to examine the relationship between DEGs and FLT3 expression, correlation analysis was taken between 22 DEGs and FLT3 in 4 datasets. Flow chart of the procedure for the literature search was described in Fig. 1.

Gene ontology and pathway enrichment analysis of DEGs

Gene Ontology (GO, http://www.geneontology.org) is a useful method commonly used to annotate genes, gene products and sequences [23, 24]. Reactome (http://www.reactome.org/) is a free, open-source, curated and peer reviewed pathway database and is intuitive bioinformatics tool for the visualization, interpretation and analysis of pathway knowledge to support basic research, genome analysis, modeling, systems biology and education [25]. DAVID database (https://david.ncifcrf.gov/) is a gene functional analysis tools aimed at systematically extracting biological meaning from large gene/user's gene [26, 27]. GO enrichment and Reactome pathway analysis were performed using DAVID online tool for analyzing the DEGs at the functional level. $\mathrm{P}<0.05$ was considered statistically significance.

\section{Protein-protein interaction (PPI) network analysis}

Search Tool for the Retrieval of Interacting Genes (STRING) is a database of known and predicted proteinprotein interactions. The interactions include direct (physical) and indirect (functional) associations; they stem from computational prediction, from knowledge transfer between organisms, and from interactions aggregated from other (primary) databases. To evaluate the interactive relationship between 22 DEGs 
Table 2. Gene ontology and Reactome pathway analysis of differentially expressed genes associated with AML

\begin{tabular}{llccll}
\hline Category & Term/Gene function & Gene count & $\%$ & P Value & Genes \\
\hline GOTERM_BP_FAT & GO:0030097 hemopoiesis & 7 & 31.82 & $9.26 E-05$ & LTF, MEIS1, EPB42, HOXB3, ADD2, AHSP, ALAS2 \\
GOTERM_BP_FAT & GO:0020027 hemoglobin metabolic process & 3 & 13.64 & $1.15 E-04$ & AHSP, EPB42, ALAS2 \\
GOTERM_BP_FAT & GO:0048534 hematopoietic or lymphoid organ development & 7 & 31.82 & $1.26 E-04$ & LTF, MEIS1, EPB42, HOXB3, ADD2, AHSP, ALAS2 \\
GOTERM_BP_FAT & GO:0002520 immune system development & 7 & 31.82 & 1.74 E-04 & LTF, MEIS1, EPB42, HOXB3, ADD2, AHSP, ALAS2 \\
GOTERM_BP_FAT & GO:0030099 myeloid cell differentiation & 5 & 22.73 & $4.40 E-04$ & LTF, MEIS1, EPB42, AHSP, ALAS2 \\
GOTERM_BP_FAT & GO:0006811 ion transport & 7 & 31.82 & 0.001 & SLC4A1, RHD, CXCL12, SLC6A8, LTF, CA1, ADD2 \\
GOTERM_BP_FAT & GO:0061515 myeloid cell development & 3 & 13.64 & 0.002 & LTF, MEIS1, EPB42 \\
GOTERM_BP_FAT & GO:0055072 iron ion homeostasis & 3 & 13.64 & 0.003 & EPB42, LTF, ALAS2 \\
GOTERM_BP_FAT & GO:0055080 cation homeostasis & 5 & 22.73 & 0.005 & CXCL12, SLC4A1, LTF, EPB42, ALAS2 \\
GOTERM_BP_FAT & GO:0030218 erythrocyte differentiation & 3 & 13.64 & 0.005 & AHSP, EPB42, ALAS2 \\
GOTERM_CC_FAT & GO:0030863 cortical cytoskeleton & 3 & 13.64 & 0.006 & SLC4A1, GYPC, EPB42 \\
GOTERM_CC_FAT & GO:0044448 cell cortex part & 3 & 13.64 & 0.011 & SLC4A1, GYPC, EPB42 \\
GOTERM_CC_FAT & GO:0005938 cell cortex & 3 & 13.64 & 0.038 & SLC4A1, GYPC, EPB42 \\
GOTERM_CC_FAT & GO:0005887 integral component of plasma membrane & 5 & 22.73 & 0.044 & RHD, GYPC, SLC4A1, SLC6A8, GYPA \\
GOTERM_MF_FAT & GO:0008519 ammonium transmembrane transporter activity & 1 & 4.55 & 0.019 & RHD \\
REACTOME_PATHWAY & R-HSA-1247673:Erythrocytes take up oxygen and release carbon dioxide & 2 & 9.09 & 0.010 & SLC4A1, CA1 \\
REACTOME_PATHWAY & R-HSA-1237044:Erythrocytes take up carbon dioxide and release oxygen & 2 & 9.09 & 0.015 & SLC4A1, CA1 \\
\hline
\end{tabular}

and FLT3, homeobox B4 (HOXB4), we uploaded these genes to STRING. When the experimental validation interactions score was greater than 0.4 , the interaction was considered significant.

\section{Statistical Analysis}

Statistical analysis was carried out by the software SPSS version 23.0 (IBM corporation, Armonk, NY, USA) and GraphPad Prism 5.01 software (GraphPad Software Inc, CA, USA). Comparisons of continuous variables (FLT3 experssion) between FLT3 positive and negative groups were performed using nonparametric tests (The Mann-Whitney U). Kaplan-Meier curves were depicted to estimate the profiles of survival, and the log-rank tests were carried out to compare the differences between survival curves. Spearman correlation analysis was performed between gene expression. Statistical significance was accepted when $\mathrm{P}<0.05$ in two sided.

\section{Results}

Identification of DEPS

Four gene expression profiles (E-TABM-1029, GSE15434, GSE61804 and TCGA) with FLT3 mutation information were analyzed to authenticate DEPs between FLT3-ITD positive and negative AML samples. A total of 377 probes (126 up-regulated and 251 down-regulated probes, Fig. 2A) were identified to be differentially expressed in E-TABM-1029 dataset, 106 probes(60 up-regulated and 46 down-regulated probes, Fig. 2A) differentially expressed in GSE15434 dataset, 199 probes (98 up-regulated and 101 down-regulated probes, Fig. 2A) differentially expressed in GSE61804 dataset, 882 probes (85 up-regulated and 797 downregulated probes, Fig. 2A) differentially expressed in TCGA dataset. Afterwards, 28 common overlap probes (all down-regulated), corresponding 22 common overlap genes, were taken out for subsequent analysis (Fig. 2B).

Gene ontology and pathway enrichment analysis of DEGs

We uploaded 22 DEGs to the DAVID online database for identifying overrepresented GO categories and Reactome pathways. GO analysis results showed that 22 DEGs were significantly enriched in hemopoiesis $(\mathrm{P}=9.26 \mathrm{e}-5)$, hemoglobin metabolic process $(\mathrm{P}=1.15 \mathrm{e}-4)$, and hematopoietic or lymphoid organ development biological processes $(\mathrm{P}=1.26 \mathrm{e}-4$, Table 2$)$, significantly enriched in cortical cytoskeleton $(\mathrm{P}=0.006)$, cell cortex part $(\mathrm{P}=0.011)$, and cell cortex cell component $(\mathrm{P}=0.038$, Table 2$)$, significantly enriched in ammonium transmembrane transporter activity molecular function $(\mathrm{P}=0.019$, Table 
2). Reactome pathways analysis results revealed that 22 DEGs significantly enriched in erythrocytes take up oxygen and release carbon dioxide (R-HSA-1247673, P=0.010) and erythrocytes take up carbon dioxide and release oxygen pathways (R-HSA-1237044, $\mathrm{P}=0.015$, Table 2).

\section{Survival value of 28 DEPS}

To investigate the association between the expression of 28 DEPs and patients' survival, we analyzed the prognostic value of those probes using Kaplan-Meier method for expression profile GSE12417. The median probe expression value was used as the cut-off value to compare the differences between the two groups. 28 DEPs prognostic significance was shown in Table 3. Only 5 probes (alpha hemoglobin stabilizing protein (AHSP) 219672_at, erythrocyte membrane protein band 4.2 (EPB42) 210746_s_at, glycophorin C (GYPC) 202947_s_at and hemogen (HEMGN) 223669_at and 223670_s_at) expression was associated with survival in two platforms among NK-AML patients. According to platform annotation file, AHSP, $E P B 42$ and GYPC gene have only one probe, $H E M G N$ has two probes. Therefore, HEMGN gene expression values reflect the averaged values of those probe sets in subsequent study. Prognostic analysis results suggested that high expression of four genes conferred a survival advantage to the low expression in NK-AML patients (AHSP: $\mathrm{P}=0.0317$,
Table 3. 28 DEPs prognostic significance in GSE12417 dataset

\begin{tabular}{|c|c|c|c|c|}
\hline \multirow{2}{*}{ Probe ID } & \multicolumn{2}{|c|}{ GPL570(n=79) } & \multicolumn{2}{|c|}{ GPL96\&GPL97(n=163) } \\
\hline & $\mathrm{P}$ value & HR & Pvalue & HR \\
\hline ADD2_205268_s_at & 0.032 & 4.439 & 0.276 & 1.910 \\
\hline AHSP_219672_at & 0.032 & 1.894 & 0.028 & 1.548 \\
\hline ALAS2_211560_s_at & 0.038 & 0.313 & 0.190 & 1.334 \\
\hline ARG1_206177_s_at & 0.738 & 1.657 & 0.059 & 0.868 \\
\hline C3orf80_236738_at & 0.035 & 1.392 & 0.412 & 1.465 \\
\hline CA1_205950_s_at & 0.038 & 2.813 & 0.329 & 1.130 \\
\hline COL4A5_213110_s_at & 0.868 & 0.805 & 0.554 & 0.800 \\
\hline CXCL12_209687_at & 0.073 & 0.620 & 0.036 & 0.991 \\
\hline EPB42_210746_s_at & 0.038 & 1.859 & 0.040 & 1.505 \\
\hline FAM92A1_228011_at & - & - & - & - \\
\hline GYPA_205837_s_at & 0.035 & 0.267 & 0.015 & 1.620 \\
\hline GYPA_205838_at & 0.065 & 0.383 & 0.045 & 0.613 \\
\hline GYPA_211820_x_at & 0.035 & 0.859 & 0.065 & 0.963 \\
\hline GYPA_211821_x_at & 0.035 & 2.220 & 0.024 & 0.566 \\
\hline GYPC_202947_S_at & 0.015 & 2.051 & 0.041 & 1.501 \\
\hline HEMGN_223669_at & 0.018 & 2.028 & 0.014 & 1.628 \\
\hline HEMGN_223670_s_at & 0.049 & 0.879 & 0.047 & 0.453 \\
\hline HOXB-AS3_230743_at & 0.321 & 0.664 & 0.942 & 0.761 \\
\hline HOXB-AS3_236892_s_at & 0.260 & 1.870 & 0.960 & 0.885 \\
\hline HOXB-AS3_239791_at & 0.244 & 0.362 & 0.970 & 1.178 \\
\hline HOXB3_228904_at & 0.997 & 0.725 & 0.873 & 0.811 \\
\hline LTF_202018_s_at & 0.670 & 0.790 & 0.675 & 1.093 \\
\hline MEIS1_1559477_s_at & 0.560 & 0.973 & - & - \\
\hline RHD_210586_x_at & 0.058 & 1.325 & 0.442 & 3.538 \\
\hline RHD_215819_s_at & 0.058 & 1.137 & 0.145 & 0.478 \\
\hline SELENBP1_214433_s_at & 0.203 & 2.201 & 0.065 & 1.363 \\
\hline SLC4A1_205592_at & 0.084 & 1.207 & 0.032 & 1.216 \\
\hline SLC6A8_202219_at & 0.008 & 2.059 & 0.102 & 1.319 \\
\hline SNURF_201522_x_at & 0.528 & 0.939 & 0.991 & 0.911 \\
\hline
\end{tabular}

Fig. 2. Volcano plots and Venn diagram of four datasets differential probes. A: E-TABM-1029 dataset (126 up-regulated and 251 down-regulated probes). GSE15434 dataset (60 up-regulated and 46 down-regulated probes). GSE61804 dataset (98 up-regulated and 101 down-regulated probes). TCGA dataset (85 up-regulated and 797 down-regulated probes). B: the venn diagram represents the share and unique probes and genes between 4 datasets.

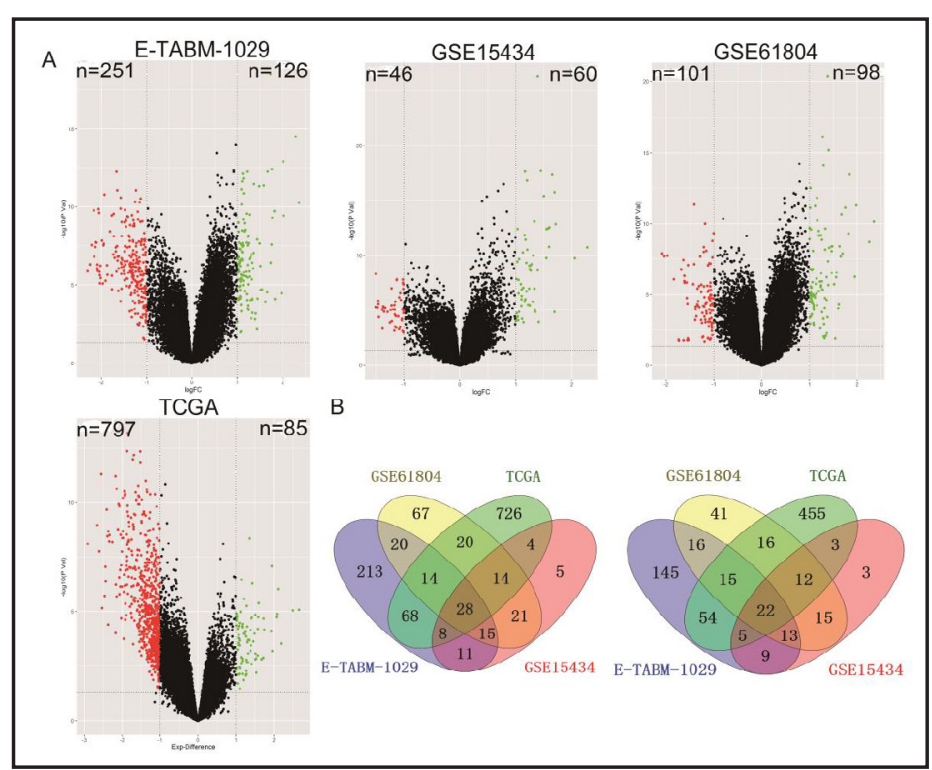




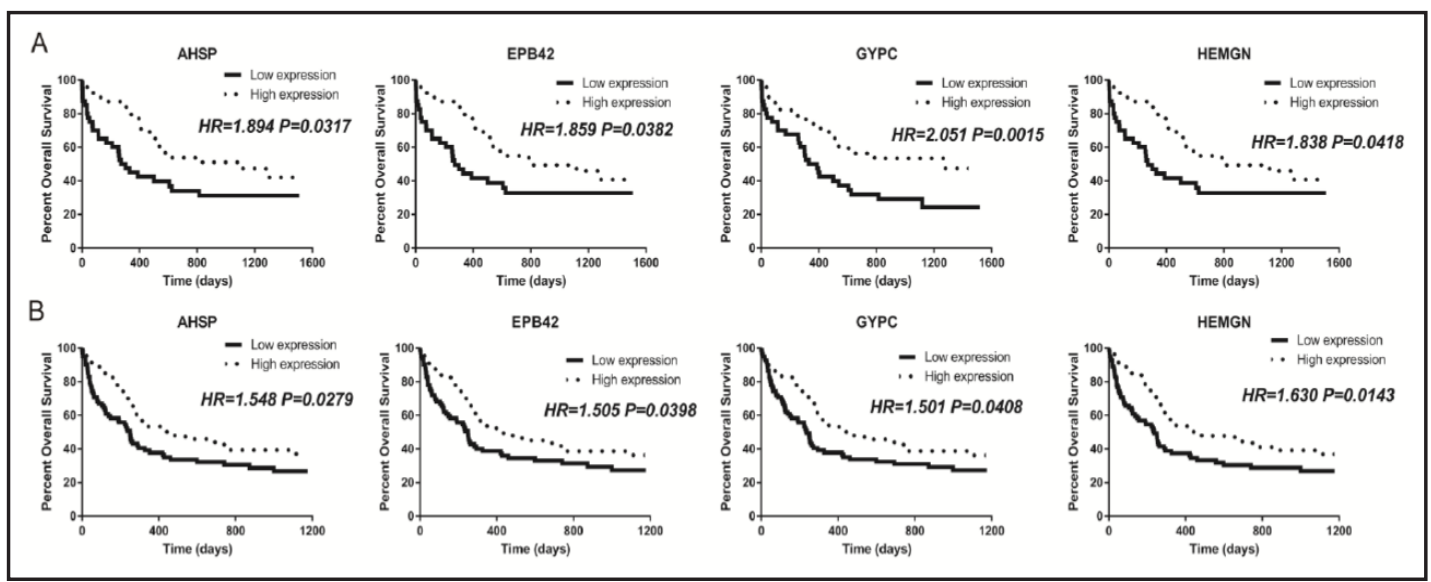

Fig. 3. Associations of $A H S P, E P B 42, G Y P C$ and $H E M G N$ gene expression with disease survivals in NK-AML patients. A: Kaplan-Meier curves of OS according to four genes expression in GSE12417 test cohort. B: Kaplan-Meier curves of OS according to four genes expression in GSE12417 validation cohort.

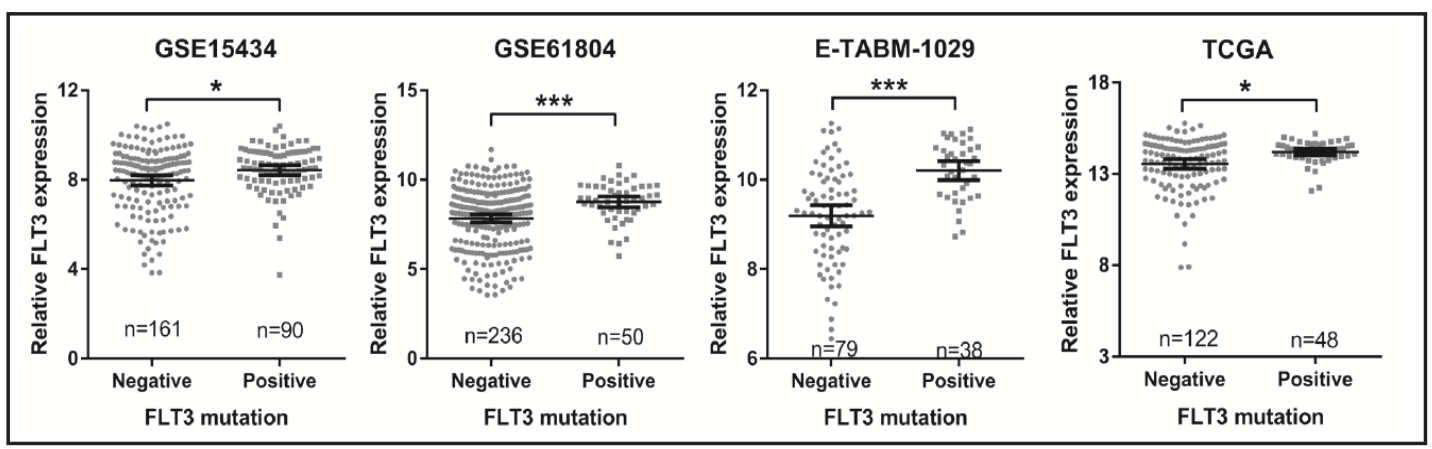

Fig. 4. The relationship of FLT3 mutation and its expression in four datasets. *represent $\mathrm{P}<0.05$, ${ }^{* *}$ represent $\mathrm{P}<0.01, * * *$ represent $\mathrm{P}<0.001$.

$\mathrm{HR}=1.894 ;$ EPB42: $\mathrm{P}=0.0382, \mathrm{HR}=1.859 ;$ GYPC: $\mathrm{P}=0.0015, \mathrm{HR}=2.051 ; H E M G N: \mathrm{P}=0.0418$, $\mathrm{HR}=1.838$ in GSE12417 test cohort, Fig.3A; AHSP: $\mathrm{P}=0.0279, \mathrm{HR}=1.548 ; E P B 42: \mathrm{P}=0.0398$, $\mathrm{HR}=1.505 ;$ GYPC: $\mathrm{P}=0.0408, \mathrm{HR}=1.501 ;$ HEMGN $\mathrm{P}=0.0143$, $\mathrm{HR}=1.630$ in GSE12417 validation cohort, Fig.3B). Given the results of prognostic analysis, four prognostic genes were included as candidate gene in following analysis.

Influence of FLT3 mutation on its mRNA expression

To investigate the relationship between FLT3 mutation status and its expression, we analyzed the difference in FLT3 expression between FLT3 genotypes using nonparametric tests in four datasets. When patients with FLT3-ITD positive, the expression of FLT3 was significantly increased. The same results was obtained in the four datasets (Fig. 4).

Correlation analysis of four differently expressed genes and FLT3 expression

The above analysis demonstrated that four differently expressed genes were associated with prognosis, but the molecular mechanism remains unclear. Therefore, we analyzed the relationship between expression of four differently expressed genes and FLT3. There was a negative correlation between the expression of FLT3 and four differently expressed genes in all the four datasets (AHSP, Fig. 5A; EPB42, Fig5B; GYPC, Fig. 5C; HEMGN, Fig. 5D).

\section{Correlation analysis of HEMGN and HOXB4 expression}

Previous study has demonstrated that HEMGN is a direct transcriptional target of HOXB4 and induces expansion of murine myeloid progenitor cells at the cellular level [28]. In contrast, it is reported that HOXB4 can indirectly affects the expression of HEMGN 


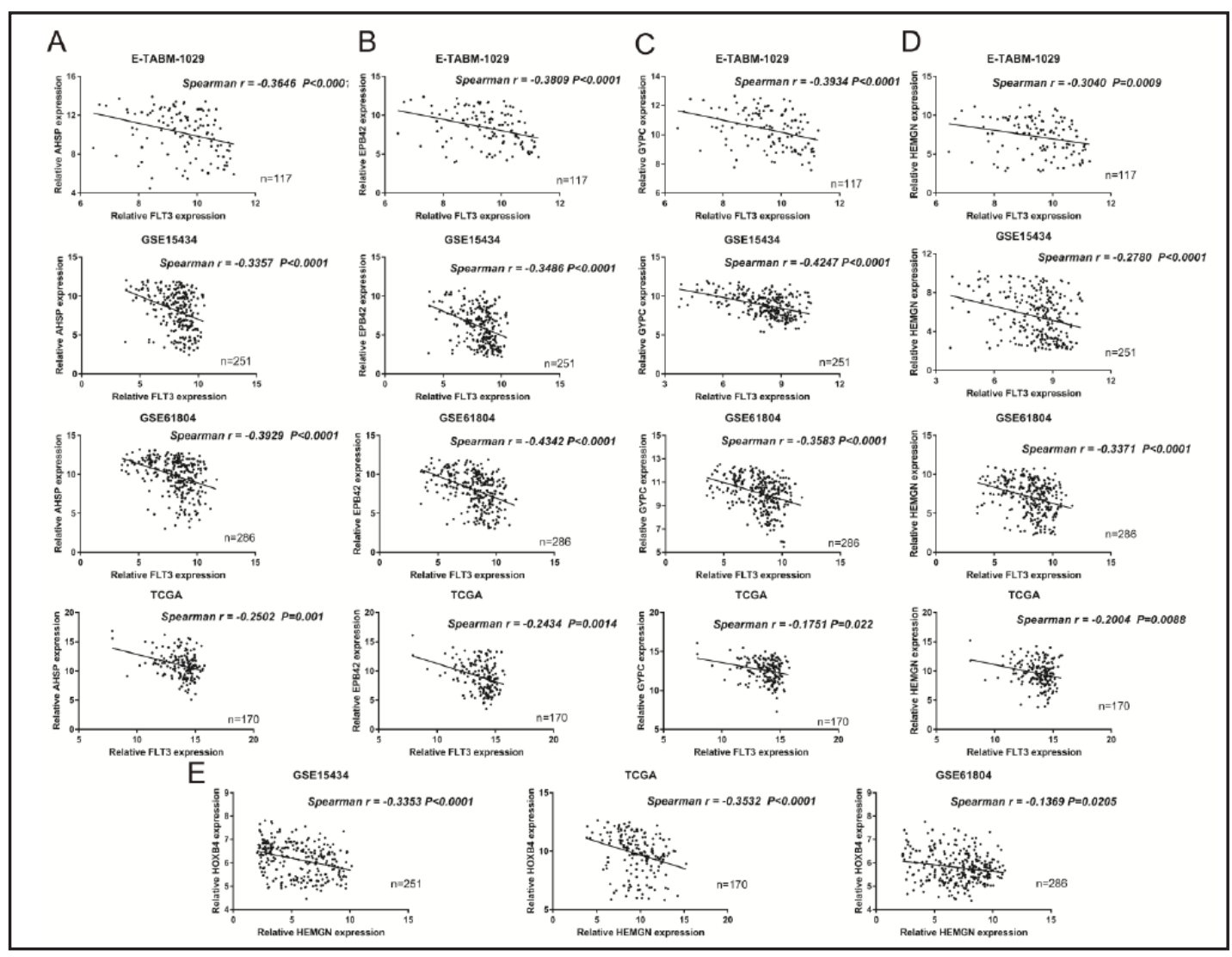

Fig. 5. Correlation analysis of AHSP (A), EPB42 (B), GYPC (C), HEMGN (D) gene and FLT3 gene in four datasets. Correlation analysis of HEMGN (E) gene and HOXB4 gene in three datasets. Due to HOXB4 gene expression was not found in E-TABM-1029 dataset, so E-TABM-1029 dataset was not included in this part.

using embryonic stem cell-derived hematopoietic stem/progenitor cells [29]. However, the relationship between expression of HEMGN and HOXB4 is still unknown yet in human samples. Thus we analyzed the relationship between HEMGN and HOXB4 expression. Given HOXB4 gene expression was not found in E-TABM-1029 dataset, so this dataset was excluded from this part. In other three datasets, we found a negative correlation between HEMGN and HOXB4 expression (GSE15434: Spearman $r=-0.3353, \mathrm{P}<0.0001$; TCGA: Spearman $\mathrm{r}=$ $-0.3532, \mathrm{P}<0.0001$; GSE61804: Spearman $\mathrm{r}=-0.1369$, $\mathrm{P}=0.0205$, Fig. 5E).

\section{PPI analysis}

Based on STRING online netword analysis website, we uploaded the 24 genes (22 DEGs, FLT3 and HOXB4) to STRING database. The results showed that 13 genes were integrated into one module and the other genes were not (Fig. 6). In the module, AHSP, EPB42, GYPC and $H E M G N$ protein were indirectly correlated with FLT3 protein. Therefore, the results also showed that HEMGN and HOXB4 were correlated and proved the above results to a certain degree.

\section{A clinically applicable four prognostics genes signature}

Due to the complexity of AML disease, single gene mutation or expression variation is insufficient to cause disease development, and so it is necessary to analyze the four genes together. The correlation analysis revealed that the four genes were highly significant in relation to each other (all Spearman $r>0.6, \mathrm{P}<0.0001$, data not shown). For the purpose of better guiding treatment of individual patients, we therefore sought to establish a method to define four prognostics genes expression prospectively. In order to achieve this, we set thresholds for each four prognostics genes calculated by mean. The mean expression levels 
Fig. 6. Protein-protein interaction network form STRING online analysis website. Network nodes represent proteins and edges represent protein-protein associations. Small nodes, protein of unknown 3D structure. Large nodes, some 3D structure is known or predicted. Colored nodes, query proteins and first shell of interactors. White nodes, second shell of interactors. Purple edges, the interactions from experimentally determined. Black edges, co-expression. Green edges, textmining.

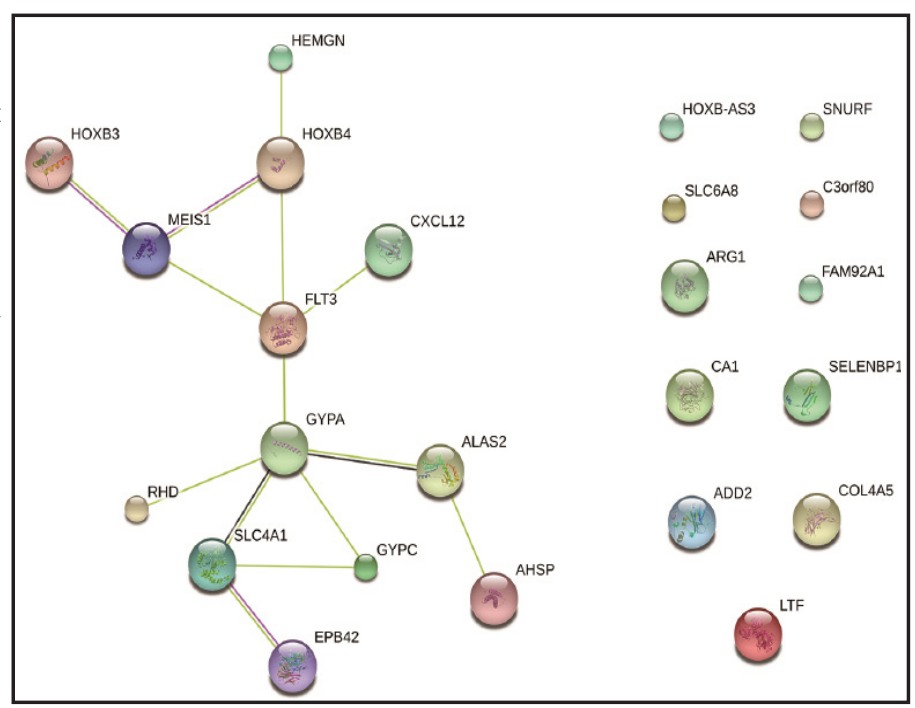

Fig. 7. A scheme for a clinically applicable four prognostics genes signature. Upper panel, expression thresholds for each 4 prognostics genes to classify NK-AML patients as being called 'positive'. Examples of NK-AML patients and the positives numbers are shown. Lower panel, Kaplan-Meier survival curves for 4 prognostic genes-low and -high patients defined by the method above in GSE12417 test cohort (A). in GSE12417 validation cohort (B). 4 prognostic genes-high patients showed significantly longer OS compared to 4 prognostic genes-low patients in both datasets. $P$ values are derived from the log-rank test.

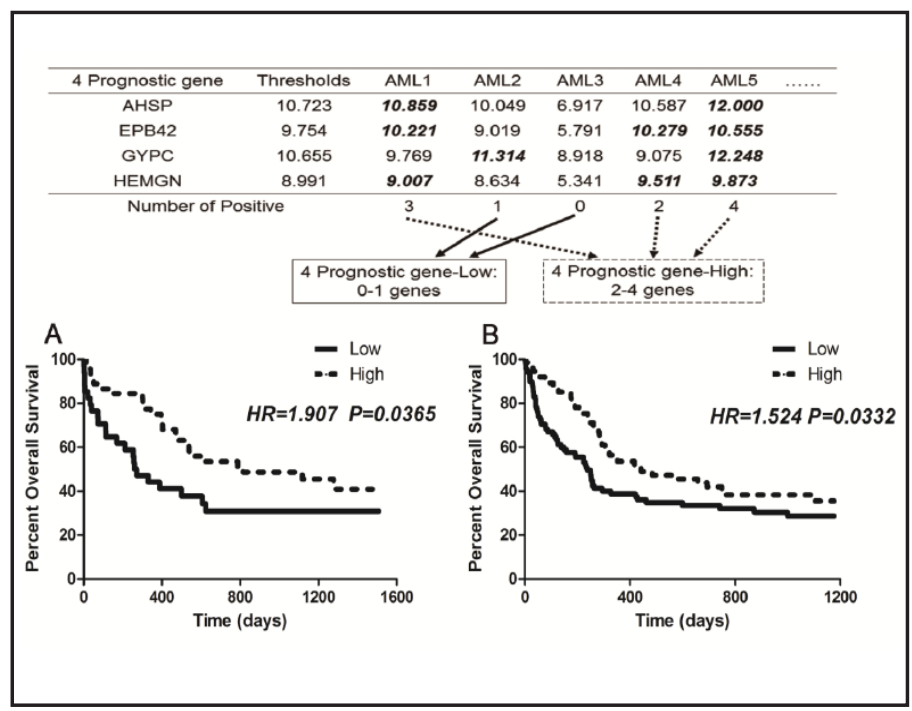

of $A H S P, E P B 42, G Y P C$, and HEMGN were 10.723, 9.754, 10.655 and 8.991, respectively, and expression above these thresholds was identified as "positive" for each gene (Fig. 7). Afterwards, AML patients were classified into 4 prognostics genes low and high based on having zero to one or more than one expressed, respectively. Kaplan-Meier curves showed that the survival of patients with 4 prognostics genes low expression defined by this classification were statistically significantly poorer than those who were high expression in GSE12417 both datasets (HR=1.907, P=0.0365 in GSE12417 test cohort, Fig 7A; HR=1.524, $\mathrm{P}=0.0332$ in GSE12417 validation cohort, Fig. 7B).

\section{Discussion}

Rational use of microarray data sets can not only be more rapid and simple analysis of a large number of genes, but also help to accurately identify the key molecular targets. In the present research, we analyzed four microarray gene expression profiles to investigate changes in gene expression associated with FLT3-ITD status and identified high expression of AHSP, EPB42, GYPC and HEMGN predicts favorable prognosis. Correlation analysis of four profiles all revealed that four genes negatively correlated with FLT3 expression. 


\section{Cellular Physiology Cell Physiol Biochem 2017;42:1973-1984 \begin{tabular}{l|l} 
DOI: 10.1159/000479837 & O 2017 The Author(s). Published by S. Karger AG, Basel \\
www.karger.com/cpb
\end{tabular} \\ Zhu et al.: Favorable Prognosis Markers in FLT3-ITD-Negative AML}

AHSP encodes a molecular chaperone, which binds reversibly to free alpha-globin and is involved in hemoglobin assembly [30]. Previous studies have reported that loss of AHSP expression results in globin precipitation in murine model and caused ineffective erythropoiesis, and more exacerbates $ß$-thalassemia [31, 32] and AHSP- knockdown cells demonstrated an increased reactive oxygen species (ROS) production and increased rate of apoptosis [33]. Moreover, AHSP gene expression is controlled by some regulatory elements, such as GATA binding protein 1 (GATA-1) [30], Organic cation transporter 1 (Oct-1) [34] and Erythroid Kruppel-like factor (EKLF) [35-37]. GATA-1 is a transcription factor that is essential for the survival and maturation of lineage-committed erythroid precursors, Oct1 and EKLF are two transcription factors that have a critical role in erythropoiesis. In our study, FLT3-ITD mutation resulted in down-regulation of AHSP expression through regulate the gene expression of FLT3, thus affecting the prognosis of NK-AML patients probably through transcription factor regulation or ROS production or the rate of apoptosis. These data suggest that there may exist new pathways influencing AHSP expression.

$E P B 42$ is an ATP-binding protein which may regulate the association of protein 3 with ankyrin and plays an important role in maintaining the structural integrity of red cell membrane. Studies have shown that EPB42 (protein 4.2) is expressed much earlier in progenitors, at around the basophilic erythroblast stage [38] and protein 4.2 deficiency results in overt haemolysis, anaemia and hereditary spherocytosis [39-41], but the exact role of protein 4.2 in red cells has not been elucidated. In this study, a high EPB42 expression predicted a favorable prognosis in AML and may be related to the interactions with CD47 $[42,43]$ and cytoskeletal protein ankyrin [44].

GYPC is an integral membrane glycoprotein and is unique among the glycophorin genes in two respects: First, GYPC encodes two erythrocyte surface glycoproteins in human, glycophorin C (GPC) and glycophorin D (GPD) via initiation of translation at two separate start codons on a single transcript [45]. Second, its sequence is not homologous to any other gene, while glycophorin A (GYPA), glycophorin B (GYPB), and glycophorin E (GYPE) are all paralogous $[46,47]$. Recent studies have shown that GYPC is a biomarker in breast cancer between high-risk and low-risk group using whole-genome methylation analysis [48] and is a major erythrocyte receptor for the rodent malaria parasite plasmodium berghei [49]. However, there is only a single study about its relationship with acute leukemia. The study shown that high GYPC gene expression was associated with an unfavorable outcome in acute lymphoblastic leukemia patients [50]. This is in contradiction to our findings which found high GYPC gene expression was associated with a favorable prognosis in AML and may be caused by the different disease type.

HEMGN gene maps to chromosome 9q22 and encodes a novel nuclear protein, which was first identified in 2001. K-F Wu's results showed that different expression patterns of HEMGN in various leukemia cell lines, and also found HEMGN gene significantly higher expression in de novo AML patients than that in the normal donors and lower HEMGN expression level was associated with a favorable therapy response [51]. However,knockdown of HEMGN gene by RNAi in leukemia cell lines showed that inhibition of HEMGN gene expression could inhibit the growth [52] and promote the differentiation of hematopoietic cells through increased p21 and reduced c-myb expression [51], or activation of nuclear factor-kB [53]. To some extent, these explains the inverse relationship between HEMGN expression and the therapy response, but the precise mechanism needs further verification.

In view of the above analysis, FLT3-ITD was an independent predictor of higher relapse rate and poorer OS, but the mechanism by which this mutation affects prognosis is still vague. Thus we postulate that FLT3-ITD mutation may influence the disease prognosis of AML possibly by decreasing the expression of AHSP, EPB42, GYPC and HEMGN gene expression. Moreover, more experiments will be conducted to explore the exact molecule mechanism of the four genes in AML patients. 


\section{Cellular Physiology Cell Physiol Biochem 2017;42:1973-1984 \\ \begin{tabular}{ll|l} 
DOI: 10.1159/000479837 & $\begin{array}{l}\text { O 2017 The Author(s). Published by S. Karger AG, Basel } \\
\text { www.karger.com/cpb }\end{array}$ \\
and Biochemistry Published online: August 07, 2017 &
\end{tabular}}

Zhu et al.: Favorable Prognosis Markers in FLT3-ITD-Negative AML

\section{Acknowledgments}

This project was supported by Chinese National Science Foundation (No.81673518), Special topic of the major subject of national science and technology (2013ZX09509-107), Hainan Provincial Natural Science Foundation of China (310148), Haikou key scientific and technological projects (2012-074), and Funds for Hunan education department program (No. 12K006).

\section{Disclosure Statement}

The authors declare that they have no conflict of interests.

\section{References}

1 Grove CS, Vassiliou GS: Acute myeloid leukaemia: A paradigm for the clonal evolution of cancer? Dis Model Mech 2014;7:941-951.

-2 Dohner H, Weisdorf DJ, Bloomfield CD: Acute myeloid leukemia. N Engl J Med 2015;373:1136-1152.

-3 Zhang R, Yang W, Li YC, Zhang GJ, Yao K, Hu R, Wu B: The opn gene polymorphism confers the susceptibility and response to ara-c based chemotherapy in chinese aml patients. Cell Physiol Biochem 2015;35:175-183.

-4 Trivedi R, Muller GA, Rathore MS, Mishra DP, Dihazi H: Anti-leukemic activity of shikonin: Role of erp57 in shikonin induced apoptosis in acute myeloid leukemia. Cell Physiol Biochem 2016;39:604-616.

-5 Long B, Wang LX, Zheng FM, Lai SP, Xu DR, Hu Y, Lin DJ, Zhang XZ, Dong L, Long ZJ, Tong XZ, Liu Q: Targeting gli1 suppresses cell growth and enhances chemosensitivity in cd34+ enriched acute myeloid leukemia progenitor cells. Cell Physiol Biochem 2016;38:1288-1302.

6 Dohner H, Estey EH, Amadori S, Appelbaum FR, Buchner T, Burnett AK, Dombret H, Fenaux P, Grimwade D, Larson RA, Lo-Coco F, Naoe T, Niederwieser D, Ossenkoppele GJ, Sanz MA, Sierra J, Tallman MS, Lowenberg B, Bloomfield CD, European L: Diagnosis and management of acute myeloid leukemia in adults: Recommendations from an international expert panel, on behalf of the european leukemianet. Blood 2010;115:453-474.

7 Xu LH, Guo Y, Zhang XL, Chen JJ, Hu SY: Blood-based circulating micrornas are potential diagnostic biomarkers for leukemia: Result from a meta-analysis. Cell Physiol Biochem 2016;38:939-949.

8 Lu Y, Wu D, Wang J, Li Y, Ma D, Chai X, Kang Q: Identification of heme oxygenase-1 as a novel predictor of hematopoietic stem cell transplantation outcomes in acute leukemia. Cell Physiol Biochem 2016;39:14951502.

-9 Ley TJ, Ding L, Walter MJ, McLellan MD, Lamprecht T, Larson DE, Kandoth C, Payton JE, Baty J, Welch J, Harris CC, Lichti CF, Townsend RR, Fulton RS, Dooling DJ, Koboldt DC, Schmidt H, Zhang Q, Osborne JR, Lin L, O'Laughlin M, McMichael JF, Delehaunty KD, McGrath SD, Fulton LA, Magrini VJ, Vickery TL, Hundal J, Cook LL, Conyers JJ, Swift GW, Reed JP, Alldredge PA, Wylie T, Walker J, Kalicki J, Watson MA, Heath S, Shannon WD, Varghese N, Nagarajan R, Westervelt P, Tomasson MH, Link DC, Graubert TA, DiPersio JF, Mardis ER, Wilson RK: Dnmt3a mutations in acute myeloid leukemia. N Engl J Med 2010;363:2424-2433.

$\checkmark 10$ Delhommeau F, Dupont S, Della Valle V, James C, Trannoy S, Masse A, Kosmider O, Le Couedic JP, Robert F, Alberdi A, Lecluse Y, Plo I, Dreyfus FJ, Marzac C, Casadevall N, Lacombe C, Romana SP, Dessen P, Soulier J, Viguie F, Fontenay M, Vainchenker W, Bernard OA: Mutation in tet2 in myeloid cancers. N Engl J Med 2009;360:2289-2301.

-11 Cancer Genome Atlas Research N: Genomic and epigenomic landscapes of adult de novo acute myeloid leukemia. N Engl J Med 2013;368:2059-2074.

12 Platt MY, Fathi AT, Borger DR, Brunner AM, Hasserjian RP, Balaj L, Lum A, Yip S, Dias-Santagata D, Zheng Z, Le LP, Graubert TA, Iafrate AJ, Nardi V: Detection of dual idh1 and idh2 mutations by targeted next-generation sequencing in acute myeloid leukemia and myelodysplastic syndromes. J Mol Diagn 2015;17:661-668.

13 Metzeler KH, Becker H, Maharry K, Radmacher MD, Kohlschmidt J, Mrozek K, Nicolet D, Whitman SP, Wu YZ, Schwind S, Powell BL, Carter TH, Wetzler M, Moore JO, Kolitz JE, Baer MR, Carroll AJ, Larson RA, 


\section{Cellular Physiology Cell Physiol Biochem 2017;42:1973-1984

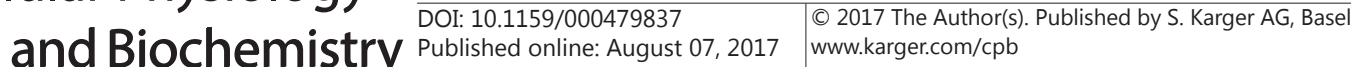 \\ Zhu et al.: Favorable Prognosis Markers in FLT3-ITD-Negative AML}

Caligiuri MA, Marcucci G, Bloomfield CD: Asxl1 mutations identify a high-risk subgroup of older patients with primary cytogenetically normal aml within the eln favorable genetic category. Blood 2011;118:69206929.

14 Van Vlierberghe P, Patel J, Abdel-Wahab O, Lobry C, Hedvat CV, Balbin M, Nicolas C, Payer AR, Fernandez HF, Tallman MS, Paietta E, Melnick A, Vandenberghe P, Speleman F, Aifantis I, Cools J, Levine R, Ferrando A: Phf6 mutations in adult acute myeloid leukemia. Leukemia 2011;25:130-134.

-15 Patel JP, Gonen M, Figueroa ME, Fernandez H, Sun Z, Racevskis J, Van Vlierberghe P, Dolgalev I, Thomas S, Aminova O, Huberman K, Cheng J, Viale A, Socci ND, Heguy A, Cherry A, Vance G, Higgins RR, Ketterling RP, Gallagher RE, Litzow M, van den Brink MR, Lazarus HM, Rowe JM, Luger S, Ferrando A, Paietta E, Tallman MS, Melnick A, Abdel-Wahab 0, Levine RL: Prognostic relevance of integrated genetic profiling in acute myeloid leukemia. N Engl J Med 2012;366:1079-1089.

16 Wang X, Wang Y: Ginsenoside rh2 mitigates pediatric leukemia through suppression of bcl-2 in leukemia cells. Cell Physiol Biochem 2015;37:641-650.

17 Saleh AM, Aljada A, El-Abadelah MM, Sabri SS, Zahra JA, Nasr A, Aziz MA: The pyridone-annelated isoindigo (5'-cl) induces apoptosis, dysregulation of mitochondria and formation of ros in leukemic hl-60 cells. Cell Physiol Biochem 2015;35:1958-1974.

18 Levis M: Flt3 mutations in acute myeloid leukemia: What is the best approach in 2013? HematologyAmerican Society of Hematology Education Program 2013:220-226.

19 Kolesnikov N, Hastings E, Keays M, Melnichuk O, Tang YA, Williams E, Dylag M, Kurbatova N, Brandizi M, Burdett T, Megy K, Pilicheva E, Rustici G, Tikhonov A, Parkinson H, Petryszak R, Sarkans U, Brazma A: Arrayexpress update--simplifying data submissions. Nucleic Acids Res 2014;43:D1113-D1116.

20 Barrett T, Wilhite SE, Ledoux P, Evangelista C, Kim IF, Tomashevsky M, Marshall KA, Phillippy KH, Sherman PM, Holko M, Yefanov A, Lee H, Zhang NG, Robertson CL, Serova N, Davis S, Soboleva A: Ncbi geo: Archive for functional genomics data sets-update. Nucleic Acids Res 2013;41:D991-D995.

-21 Weinstein JN, Collisson EA, Mills GB, Shaw KR, Ozenberger BA, Ellrott K, Shmulevich I, Sander C, Stuart JM: The cancer genome atlas pan-cancer analysis project. Nat Genet 2013;45:1113-1120.

22 Larsson 0, Wahlestedt C, Timmons JA: Considerations when using the significance analysis of microarrays (sam) algorithm. BMC Bioinformatics 2005;6:129.

23 Ashburner M, Ball CA, Blake JA, Botstein D, Butler H, Cherry JM, Davis AP, Dolinski K, Dwight SS, Eppig JT, Harris MA, Hill DP, Issel-Tarver L, Kasarskis A, Lewis S, Matese JC, Richardson JE, Ringwald M, Rubin GM, Sherlock G: Gene ontology: Tool for the unification of biology. The gene ontology consortium. Nat Genet 2000;25:25-29.

24 Gene Ontology C: The gene ontology (go) project in 2006. Nucleic Acids Res 2006;34:D322-326.

-25 Croft D, O'Kelly G, Wu G, Haw R, Gillespie M, Matthews L, Caudy M, Garapati P, Gopinath G, Jassal B, Jupe S, Kalatskaya I, Mahajan S, May B, Ndegwa N, Schmidt E, Shamovsky V, Yung C, Birney E, Hermjakob H, D'Eustachio P, Stein L: Reactome: A database of reactions, pathways and biological processes. Nucleic Acids Res 2011;39:D691-697.

26 Huang da W, Sherman BT, Lempicki RA: Bioinformatics enrichment tools: Paths toward the comprehensive functional analysis of large gene lists. Nucleic Acids Res 2009;37:1-13.

-27 Huang da W, Sherman BT, Lempicki RA: Systematic and integrative analysis of large gene lists using david bioinformatics resources. Nat Protoc 2009;4:44-57.

28 Jiang J, Yu H, Shou Y, Neale G, Zhou S, Lu TH, Sorrentino BP: Hemgn is a direct transcriptional target of hoxb4 and induces expansion of murine myeloid progenitor cells. Blood 2010;116:711-719.

29 Oshima M, Endoh M, Endo TA, Toyoda T, Nakajima-Takagi Y, Sugiyama F, Koseki H, Kyba M, Iwama A, Osawa M: Genome-wide analysis of target genes regulated by hoxb4 in hematopoietic stem and progenitor cells developing from embryonic stem cells. Blood 2011;117:e142-150.

-30 Ahn D-g, Kourakis MJ, Rohde LA, Silver LM, Ho RK: An abundant erythroid protein that stabilizes free alpha-haemoglobin. Nature 2002;417:758-763.

- 31 Kong Y, Zhou S, Kihm AJ, Katein AM, Yu X, Gell DA, Mackay JP, Adachi K, Foster-Brown L, Louden CS, Gow AJ, Weiss MJ: Loss of $\alpha$-hemoglobin-stabilizing protein impairs erythropoiesis and exacerbates $\beta$-thalassemia. J Clin Invest 2004;114:1457-1466.

-32 Favero ME, Costa FF: Alpha-hemoglobin-stabilizing protein: An erythroid molecular chaperone. Biochem Res Int 2011;2011:1-7. 


\section{Cellular Physiology Cell Physiol Biochem 2017;42:1973-1984 \begin{tabular}{l|l|l|l} 
DOI: 10.1159/000479837 & C 2017 The Author(s). Published by S. Karger AG, Basel \\
www.kargercom/cpb
\end{tabular}

-33 Pinho FO, de Albuquerque DM, Olalla Saad ST, Costa FF: Reduction of ahsp synthesis in hemin-induced k562 cells and epo-induced cd34(+) cells leads to alpha-globin precipitation, impairment of normal hemoglobin production, and increased cell death. Exp Hematol 2008;36:265-272.

-34 Gallagher PG, Liem RI, Wong E, Weiss MJ, Bodine DM: Gata-1 and oct-1 are required for expression of the human alpha-hemoglobin-stabilizing protein gene. J Biol Chem 2005;280:39016-39023.

-35 Hodge D, Coghill E, Keys J, Maguire T, Hartmann B, McDowall A, Weiss M, Grimmond S, Perkins A: A global role for eklf in definitive and primitive erythropoiesis. Blood 2006;107:3359-3370.

-36 Keys JR, Tallack MR, Hodge DJ, Cridland SO, David R, Perkins AC: Genomic organisation and regulation of murine alpha haemoglobin stabilising protein by erythroid kruppel-like factor. Br J Haematol 2007;136:150-157.

-37 Pilon AM, Nilson DG, Zhou D, Sangerman J, Townes TM, Bodine DM, Gallagher PG: Alterations in expression and chromatin configuration of the alpha hemoglobin-stabilizing protein gene in erythroid kruppel-like factor-deficient mice. Mol Cell Biol 2006;26:4368-4377.

- 38 Leberbauer C, Boulme F, Unfried G, Huber J, Beug H, Mullner EW: Different steroids co-regulate long-term expansion versus terminal differentiation in primary human erythroid progenitors. Blood 2005;105:85-94.

- 39 Ghanem A, Pothier B, Marechal J, Ducluzeau MT, Morle L, Alloisio N, Feo C, Ben Abdeladhim A, Fattoum S, Delaunay J: A haemolytic syndrome associated with the complete absence of red cell membrane protein 4.2 in two tunisian siblings. Br J Haematol 1990;75:414-420.

40 Hayette S, Dhermy D, dos Santos ME, Bozon M, Drenckhahn D, Alloisio N, Texier P, Delaunay J, Morle L: A deletional frameshift mutation in protein 4.2 gene (allele 4.2 lisboa) associated with hereditary hemolytic anemia. Blood 1995;85:250-256.

41 Ideguchi H, Nishimura J, Nawata H, Hamasaki N: A genetic defect of erythrocyte band 4.2 protein associated with hereditary spherocytosis. Br J Haematol 1990;74:347-353.

-42 Bruce LJ, Ghosh S, King MJ, Layton DM, Mawby WJ, Stewart GW, Oldenborg PA, Delaunay J, Tanner MJ: Absence of cd47 in protein 4.2-deficient hereditary spherocytosis in man: An interaction between the rh complex and the band 3 complex. Blood 2002;100:1878-1885.

43 Mouro-Chanteloup I, Delaunay J, Gane P, Nicolas V, Johansen M, Brown EJ, Peters LL, Van Kim CL, Cartron JP, Colin Y: Evidence that the red cell skeleton protein 4.2 interacts with the rh membrane complex member cd47. Blood 2003;101:338-344.

44 Satchwell TJ, Shoemark DK, Sessions RB, Toye AM: Protein 4.2: A complex linker. Blood Cells Molecules and Diseases 2009;42:201-210.

45 Le Van Kim C, Piller V, Cartron JP, Colin Y: Glycophorins c and d are generated by the use of alternative translation initiation sites. Blood 1996;88:2364-2365.

-46 Tanner MJ, High S, Martin PG, Anstee DJ, Judson PA, Jones TJ: Genetic variants of human red-cell membrane sialoglycoprotein beta. Study of the alterations occurring in the sialoglycoprotein-beta gene. Biochem J 1988;250:407-414.

47 Wilder JA, Hewett EK, Gansner ME: Molecular evolution of gypc: Evidence for recent structural innovation and positive selection in humans. Mol Biol Evol 2009;26:2679-2687.

-48 Zhang C, Zhao H, Li J, Liu H, Wang F, Wei Y, Su J, Zhang D, Liu T, Zhang Y: The identification of specific methylation patterns across different cancers. PLoS One 2015;10:e0120361.

-49 Yiangou L, Montandon R, Modrzynska K, Rosen B, Bushell W, Hale C, Billker O, Rayner JC, Pance A: A stem cell strategy identifies glycophorin $\mathrm{c}$ as a major erythrocyte receptor for the rodent malaria parasite plasmodium berghei. PLoS One 2016;11:e0158238.

-50 Zhang JB, Li XH, Ning F, Guo XS: [relationship between expression of gypc and trip3 genes and prognosis of acute lymphoblastic leukemia in children]. Zhongguo Dang Dai Er Ke Za Zhi 2009;11:29-32.

-51 An LL, Li G, Wu KF, Ma XT, Zheng GG, Qiu LG, Song YH: High expression of edag and its significance in aml. Leukemia 2005;19:1499-1502.

-52 Ling B, Zhou Y, Feng D, Shen G, Gao T, Shi Y, Wei H, Tian Z: Down-regulation of edag expression by retrovirus-mediated small interfering rna inhibits the growth and il-8 production of leukemia cells. Oncol Rep 2007;18:659-664.

-53 Li CY, Zhan YQ Xu CW, Xu WX, Wang SY, Lv J, Zhou Y, Yue PB, Chen B, Yang XM: Edag regulates the proliferation and differentiation of hematopoietic cells and resists cell apoptosis through the activation of nuclear factor-kappa b. Cell Death Differ 2004;11:1299-1308. 